\title{
Deep breathing improves blunted baroreflex sensitivity even after 30 years of type 1 diabetes
}

\author{
M. Rosengård-Bärlund • L. Bernardi • J. Holmqvist • \\ G. Debarbieri • M. Mäntysaari • C.-G. af Björkesten • \\ C. Forsblom • P.-H. Groop • the FinnDiane Study Group
}

Received: 8 November 2010 / Accepted: 1 April 2011 / Published online: 3 May 2011

(C) Springer-Verlag 2011

\begin{abstract}
Aims/hypotheses Cardiovascular autonomic neuropathy is associated with increased morbidity in patients with type 1 diabetes. Although it is conventionally considered to be an organic, irreversible disorder, we previously demonstrated in patients with short-duration type 1 diabetes that reduced baroreflex sensitivity (BRS) could be corrected by slow, deep breathing, indicating a functional component to the disorder. We have now tested whether autonomic abnormalities in long-term diabetes progress to a stage that cannot be modified by functional manoeuvres, indicating a switch towards predominantly organic dysfunction.

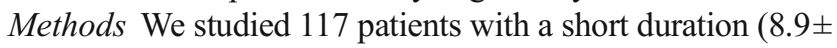

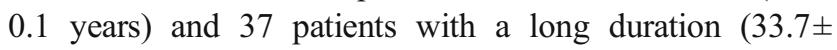

M. Rosengård-Bärlund · J. Holmqvist • C.-G. af Björkesten •

C. Forsblom · P.-H. Groop

Department of Medicine, Division of Nephrology,

Helsinki University Central Hospital,

Helsinki, Finland

M. Rosengård-Bärlund $\cdot$ L. Bernardi $\cdot J$. Holmqvist •

C.-G. af Björkesten • C. Forsblom • P.-H. Groop ( $\square)$

Folkhälsan Research Center, Biomedicum Helsinki (C318b),

University of Helsinki,

PO Box 63, Helsinki FIN-00014, Finland

e-mail: per-henrik.groop@helsinki.fi

L. Bernardi • G. Debarbieri

Department of Internal Medicine,

University of Pavia and IRCCS S. Matteo,

Pavia, Italy

M. Mäntysaari

Aeromedical Centre (AMC), The Finnish Defence Forces,

Helsinki, Finland

P.-H. Groop

The Baker IDI Heart and Diabetes Institute,

Melbourne, VIC, Australia
0.5 years) of type 1 diabetes, 73 healthy controls and 12 hearttransplanted participants (surgical heart denervation). An autonomic score was calculated from autonomic function tests. Spectral analysis of heart rate and blood pressure variability, and BRS, were obtained from recordings during normal (15 breaths per min) and slow, deep (six breaths per min) controlled breathing.

Results BRS was reduced in all patients, but more in patients with a long duration of diabetes or with increasing autonomic involvement, although the effect of duration disappeared after adjustment for age. Slow breathing increased the BRS to the level of the control participants at a normal rate of breathing (15 per min) in all patients except those with an abnormal autonomic score.

Conclusions/interpretation Patients with type 1 diabetes have a blunted BRS that in the majority of patients can be restored by slow breathing, irrespective of disease duration. Even after a long duration of diabetes, the abnormal BRS is at least in part of functional origin.

Keywords Autonomic dysfunction - Baroreflex sensitivity · Cardiovascular autonomic neuropathy - Diabetic neuropathy $\cdot$ Heart rate variability · Hypertension · Type 1 diabetes mellitus

$\begin{array}{ll}\text { Abbreviations } \\ \text { BRS } & \text { Baroreflex sensitivity } \\ \text { CAN } & \text { Cardiovascular autonomic neuropathy } \\ \text { HRV } & \text { Heart rate variability } \\ \text { HF } & \text { High-frequency } \\ \text { LF } & \text { Low-frequency } \\ \text { nHF } & \text { Normalised high-frequency } \\ \text { nLF } & \text { Normalised low-frequency } \\ \text { SBP } & \text { Systolic blood pressure } \\ \text { SDNN } & \text { Standard deviation of all RR intervals }\end{array}$




\section{Introduction}

Cardiovascular autonomic neuropathy (CAN) is a severe complication of diabetes, associated with an increased risk of late complications of diabetes [1-4] and premature death [5]. Diabetic neuropathy has conventionally been considered to be an irreversible, organic process [6]. However, in a previous study we demonstrated that, in patients with type 1 diabetes and early autonomic impairment as indicated by reduced baroreflex sensitivity (BRS), the BRS was in fact normalised during slow breathing [7]. The importance of this finding lies in the fact that reduced BRS is an established marker of poor prognosis in cardiovascular medicine [8-10], and also an early marker of autonomic alteration in diabetes [11-13]. However, our findings indicated that, at least at an early stage of the disease process, the observed autonomic abnormalities might be mainly functional and potentially correctable by appropriate interventions [14-18]. In addition, considering the notion that progression of the disease is not invariable [19], it is possible to hypothesise that a reduced BRS might not inevitably progress to $\mathrm{CAN}$, and perhaps only at a later stage of the disease may the functional nature of early autonomic dysfunction advance to organic, irreversible neuropathy.

Therefore, the aim of this study was to test whether autonomic dysfunction, as indicated by reduced BRS, progresses along with increasing duration of diabetes to a stage where it might no longer be improved by a functional manoeuvre, indicating a switch towards a more or entirely organic lesion. To answer this question, we examined the impact of diabetes duration and age, and the occurrence of abnormalities in the cardiovascular autonomic tests, on the response of BRS to slow breathing in patients with type 1 diabetes of long and short duration.

\section{Methods}

Study population In this paper, we specifically studied patients with type 1 diabetes $(n=37)$ with a long duration of diabetes ( $33.7 \pm 0.5$ years) as well as an age- and sexmatched control group $(n=37)$. The patients with a long duration of diabetes had initially participated in another study and were recruited to the present study at a follow-up visit. The original study comprised 110 patients at baseline in 1985, out of whom 83 were re-studied in 1996 [20]. These participants were diagnosed with type 1 diabetes between 1968 and 1978 and had an age at onset of less than 15 years. After exclusion of those taking beta-blocker medication, a total of 40 patients agreed to take part in the present study. One patient was excluded due to an unsuccessful Finapres recording, one because of an un- known neurological disease and one because of a kidney transplant.

The data from the patients with a long duration of type 1 diabetes were compared with previously published data on patients with a short duration of type 1 diabetes $(n=117$, diabetes duration $8.9 \pm 0.1$ years), an age- and sex-matched control group $(n=36)$ and a group of heart-transplanted participants $(n=12)$ [7]. The group of heart-transplanted individuals served as a model of definitive denervation in the figures, and the data were not used in the statistical analyses. The selection criteria for the participants with a short duration of diabetes were diabetes diagnosed before the age of 35 years, duration of diabetes of 6-12 years and age at the time of inclusion between 18 and 35 years. Type 1 diabetes was defined as C-peptide deficiency $(<0.03 \mathrm{nmol} / \mathrm{l})$ and initiation of permanent insulin treatment within 1 year after the diagnosis of diabetes. None of these patients was on beta-blocker medication. The study protocols were approved by the Ethics Committee of Helsinki University Hospital and by the Ethics Committee of the University in Pavia, Italy (for the heart-transplanted participants). All participants gave their written informed consent before taking part.

Protocol for the autonomic testing The autonomic testing was performed during standardised conditions, in a quiet room, at a temperature between $19^{\circ} \mathrm{C}$ and $23^{\circ} \mathrm{C}$, between 08:00 and 14:00 hours. Prior to the examination, the participants were instructed to refrain from alcohol for $36 \mathrm{~h}$, and from caffeinated beverages and cigarettes for $12 \mathrm{~h}$. A light meal was permitted $2 \mathrm{~h}$ before testing. If an individual experienced symptomatic or measured hypoglycaemia during the $24 \mathrm{~h}$ before the test, the examination was postponed. No medications were discontinued for the purpose of the study. An ECG was recorded using a bipolar precordial lead. Continuous blood pressure monitoring was performed using a Finapres 2300 digital plethysmograph (Ohmeda, Louisville, CO, USA) on the middle finger of the right hand held at heart level. Self-calibration of the Finapres was performed immediately before each data acquisition. Recorded signals were digitised with a 12-bit resolution at a sampling rate of $200 \mathrm{~Hz}$ (WinAcq data acquisition system; Absolute Aliens, Turku, Finland). Ectopic beats were recognised visually and corrected by linear interpolation. The subsequent offline signal processing was performed using WinCPRS software (Absolute Aliens).

The autonomic function was assessed by a set of four cardiovascular autonomic function tests: (1) the expiration/ inspiration ratio of RR interval during slow, deep breathing; (2) the maximum/minimum 30:15 ratio of RR interval during active standing; (3) the systolic blood pressure response to standing; and (4) the maximum/minimum ratio of RR interval during a Valsalva manoeuvre. The four tests 
were graded according to Finnish age-specific reference values [21] ( 0 if normal, 1 if abnormal), giving an autonomic score of between 0 and 4 . The participants with type 1 diabetes were divided into three groups: CAN-0 (autonomic score $=0$ ), CAN-1 (autonomic score=1), and CAN-2 (autonomic score $>1$ ). The timing of the breathing was given by the measurement protocol in the WinCPRS software. In addition, the technician instructed the participant verbally, and monitored the respiration visually and with the aid of a stopwatch. This methodology conforms to the most recent consensus statement on diabetic neuropathy [22].

Spectral analysis of heart rate and blood pressure variability and assessment of the BRS Data acquisition and analysis was performed as previously described [7]. ECG and continuous blood pressure were recorded in the supine position during $5 \mathrm{~min}$ of spontaneous breathing, 5 min of controlled breathing (15 breaths per min) and $1 \mathrm{~min}$ of slow deep breathing (six breaths per min). Power spectral analysis was performed with fast Fourier transformation, allowing us to obtain the power in the lowfrequency (LF; $0.04-0.15 \mathrm{~Hz}$ ) and high-frequency (HF; $0.15-0.40 \mathrm{~Hz}$ ) bands, as well as the low-to-high frequency ratio $(\mathrm{LF} / \mathrm{HF})$ for the $\mathrm{RR}$ interval. Normalised units of the $\mathrm{LF}$ and $\mathrm{HF}$ bands (nLF and $\mathrm{nHF}$ ) were calculated as follows: $n L F=L F$ power/(LF $+\mathrm{HF}$ powers $)$, and $n H F=H F$ power/(LF+HF powers).

BRS was determined from the spontaneous fluctuations in the RR interval and systolic blood pressure (SBP) during spontaneous, controlled and deep breathing. However, because of the known effect of the fluctuations of the respiration rate on the BRS (spontaneous breathing), the comparisons were made between controlled and deep breathing. As none of the methods has been proved to be superior to the others, we used a set of four different tests and present the BRS data as the average of these methods. This proved to be a more robust estimate than the use of single tests $[7,23]$.

Regarding the sequence method, the BRS was estimated through identification of spontaneously occurring sequences of three or more consecutive heartbeats in which both the SBP and the subsequent RR intervals changed in the same direction. The minimum criterion for change was $1 \mathrm{mmHg}$ for SBP and $5 \mathrm{~ms}$ for the RR intervals. For the identified up-up (+/+) and down-down $(-/-)$ sequences with a correlation coefficient between the RR intervals and the SBP exceeding 0.85 , the regression slopes (the slopes of the lines of regression between the SBP and RR intervals) were calculated, and the average was taken as a measure of BRS $+/+$ and BRS $-/-$, respectively. The $\alpha$ coefficient (alpha LF-BRS) was calculated as the square root of the ratio between the SBP and RR interval spectral powers in the LF range $(0.04-0.15 \mathrm{~Hz})$ when the coherence was greater than 0.5 and the phase difference between the SBP and RR intervals was negative. In the transfer function method, BRS was calculated as the average value of SBP-RR crossspectrum divided by the SBP spectrum in the LF range $(0.04-0.15 \mathrm{~Hz})$, when the coherence exceeded 0.5.

Statistical analyses All statistical analyses were performed using PASW Statistics 17 (PASW, Chicago, IL, USA). The data in tables are given as mean \pm SEM or median (range) when appropriate (Table 1). The data were tested for normal distribution, and the variables were log-transformed before the statistical analyses to obtain normality. Categorical variables were analysed with Pearson's $\chi^{2}$ test.

Because there were participants with different levels of CAN in both groups of patients with type 1 diabetes, we analysed the impact of autonomic involvement and duration separately. This was done by grouping the diabetic patients according to the duration of diabetes (short or long) or in terms of CAN (CAN-0, CAN-1 or CAN-2). Owing to the small number of patients in the CAN-2 group $(n=5)$, no statistical analyses were performed, although mean and SEM are given. Regarding spectral data, the differences between the groups were tested by ANOVA, and post hoc analysis was done with Tukey's test. The differences in the BRS response to deep breathing across different groups were tested with two-way mixed-design ANOVA (factorial design to test the differences between groups, and repeated measures to test for the effect of breathing rate). In addition, because the participants' ages were unavoidably different between the two groups with diabetes of different duration, we repeated the ANOVA models after adjusting the BRS data for age. Whenever the main effect or interaction was significant, a subsequent post hoc multiple comparison with Tukey's test was performed. Statistical significance was defined as a $p$ value $\leq 0.05$.

\section{Results}

The clinical characteristics and the laboratory results are given in Table 1. Patients with a long duration of diabetes were older and had a lower age at disease onset $(p<0.001)$. Moreover, the patients with a long duration of diabetes had a higher $\mathrm{HbA}_{1 \mathrm{c}}$ level $(p<0.05)$, a lower insulin dose $(p<$ 0.05 ) and, as expected, a higher prevalence of laser-treated retinopathy $(p<0.001)$ and antihypertensive medication $(p<$ $0.001)$ than patients with a short duration. The autonomic score was normal in 126 (CAN-0), borderline in 23 (CAN1) and abnormal in five patients with diabetes (CAN-2). With increasing autonomic score, the diabetic patients had a longer disease duration and worse glycaemic control. The 
Table 1 Clinical characteristics of the patients with type 1 diabetes divided by diabetes duration and by the autonomic score

\begin{tabular}{|c|c|c|c|c|c|}
\hline \multirow[t]{2}{*}{ Clinical characteristic } & \multicolumn{2}{|c|}{$\begin{array}{l}\text { Patients with type } 1 \text { diabetes divided by } \\
\text { diabetes duration }\end{array}$} & \multicolumn{3}{|c|}{ Patients with type 1 diabetes divided by autonomic score } \\
\hline & $\begin{array}{l}\text { Long duration } \\
n=37\end{array}$ & $\begin{array}{l}\text { Short duration } \\
n=117\end{array}$ & CAN-0 $n=126$ & CAN-1 $n=23$ & CAN-2 $n=5$ \\
\hline Sex (male/female) & $18 / 19$ & $62 / 55$ & $67 / 59$ & $10 / 13$ & $3 / 2$ \\
\hline Age (years) & $42.7 \pm 0.8^{* * *}$ & $26.3 \pm 0.5$ & $29.8 \pm 0.8$ & $32.2 \pm 2.2$ & $32.5 \pm 4.3$ \\
\hline Duration of diabetes (years) & $33.7 \pm 0.5^{* * *}$ & $8.9 \pm 0.1$ & $13.8 \pm 0.9 \dagger$ & $19.9 \pm 2.7$ & $17.4 \pm 6.0$ \\
\hline Age at onset (years) & $9.0 \pm 0.5 * * *$ & $17.4 \pm 0.6$ & $16.0 \pm 0.6 \dagger$ & $12.3 \pm 1.2$ & $15.1 \pm 2.8$ \\
\hline Systolic blood pressure (mmHg) & $130 \pm 2$ & $132 \pm 1$ & $132 \pm 1$ & $131 \pm 3$ & $136 \pm 7$ \\
\hline Diastolic blood pressure $(\mathrm{mmHg})$ & $73 \pm 1 * * *$ & $78 \pm 1$ & $77 \pm 1$ & $76 \pm 1$ & $84 \pm 7$ \\
\hline $\mathrm{HbA}_{1 \mathrm{c}}(\%)$ & $8.2 \pm 0.2 *$ & $7.6 \pm 0.1$ & $7.6 \pm 0.1$ & $8.0 \pm 0.2$ & $9.4 \pm 0.2$ \\
\hline Participants with $\mathrm{HbA}_{1 \mathrm{c}}<7.5 \%$ (\%) & $50.9^{*}$ & 29.7 & 48.8 & 39.1 & 0.0 \\
\hline Insulin dose $\left(\mathrm{U} \mathrm{kg}^{-1}\right.$ day $\left.^{-1}\right)$ & $0.64 \pm 0.03 * * *$ & $0.86 \pm 0.03$ & $0.81 \pm 0.02$ & $0.75 \pm 0.05$ & $1.17 \pm 0.48$ \\
\hline Serum creatinine $(\mu \mathrm{mol} / 1)$ & $71 \pm 2$ & $70 \pm 1$ & $70 \pm 1$ & $71 \pm 3$ & $60 \pm 6$ \\
\hline Total cholesterol (mmol/l) & $4.8 \pm 0.1$ & $4.6 \pm 0.1$ & $4.7 \pm 0.1$ & $4.6 \pm 0.2$ & $4.9 \pm 0.2$ \\
\hline HDL-cholesterol (mmol/l) & $1.9 \pm 0.1$ & $1.7 \pm 0.0$ & $1.7 \pm 0.0$ & $1.8 \pm 0.1$ & $2.1 \pm 0.24$ \\
\hline LDL-cholesterol (mmol/l) & $2.3 \pm 0.1$ & $2.4 \pm 0.1$ & $2.4 \pm 0.1$ & $2.1 \pm 0.2$ & $2.1 \pm 0.2$ \\
\hline Triacylglycerol (mmol/l) & $0.90(0.20-13.90)$ & $0.95(0.41-5.17)$ & $0.93(0.20-13.90)$ & $0.98(0.40-5.17)$ & $1.80(0.85-2.50)$ \\
\hline \multicolumn{6}{|l|}{ Antihypertensive treatment $(n / \%)$} \\
\hline ACE-inhibitor/ARB & $15 / 40.5 * * *$ & $6 / 5.1$ & $11 / 8.7 \dagger$ & $8 / 34.8$ & $2 / 40$ \\
\hline Diuretic & $5 / 13.5^{*}$ & $1 / 0.9$ & $3 / 2.4 \dagger$ & $4 / 17.4$ & $0 / 0$ \\
\hline Calcium channel blocker & $2 / 5.4$ & $0 / 0$ & $1 / 0.8$ & $1 / 4.3$ & $0 / 0$ \\
\hline Laser-treated retinopathy (\%) & $35.1 * * *$ & 0.9 & $4.8 \dagger$ & 30.4 & 20.0 \\
\hline $\begin{array}{l}\text { Urinary albumin excretion rate } \\
(\mathrm{mg} / 24 \mathrm{~h})\end{array}$ & $7.3(0.0-898.1)$ & $3.4(0.4-774.1)$ & $3.5(0.0-754.0)$ & $4.9(1.1-898.1)$ & $32.7(2.5-774.1)$ \\
\hline
\end{tabular}

Data are means \pm SEM or median (range)

${ }^{*} p<0.05,{ }^{* * *} p<0.001$ long duration vs short duration; ${ }^{\dagger} p<0.05$ CAN-0 vs CAN-1

$\mathrm{ARB}$, angiotensin receptor blocker

numbers of patients with a short duration/long duration in the CAN-0, CAN-1 and CAN-2 groups were 101/25, 13/10 and $3 / 2$, respectively.

Spectral analysis and BRS During controlled breathing at 15 breaths per min, which is close to the normal range of breathing, the patients with a long duration of diabetes had markedly lower values for all absolute HRV indices compared with the patients with a short duration (Table 2). The patients with a long duration showed a lower proportion (\%) of $\mathrm{HF}$ components and a significantly higher $\mathrm{LF} / \mathrm{HF}$ ratio as well as a lower $\mathrm{SD}$ of all $\mathrm{R}-\mathrm{R}$ intervals (SDNN) and absolute power in the respiratory (HF) band compared with the patients with a short duration. The power in the LF band of SBP was increased in the diabetic patients with a normal autonomic score, but was reduced in patients with a long duration and a higher autonomic score, although the differences did not reach statistical significance (Table 2).
The average BRS during spontaneous breathing was $11.6 \pm 1.3 \mathrm{~ms} / \mathrm{mmHg}$ in the patients with a long duration of diabetes, $16.2 \pm 0.6 \mathrm{~ms} / \mathrm{mmHg}$ in those with a short duration and $19.9 \pm 1.3 \mathrm{~ms} / \mathrm{mmHg}$ in the control participants, respectively ( $p<0.05$ for all comparisons between groups). Adjustment for age abolished the difference between the groups with diabetes, whereas the difference between the control participants and the groups with diabetes remained significant (data not shown).

During controlled breathing at 15 breaths per min, the BRS was clearly reduced in patients with type 1 diabetes overall compared with the controls, and the BRS was lower in patients with diabetes of long duration (Fig. 1a). However, slow breathing significantly increased the BRS to a level similar to that obtained in the control participants at a normal breathing rate ( 15 breaths per min) in all groups except in the heart-transplanted participants. Tested by mixed-design ANOVA, both the main effects of the intervention (change in breathing rate) and the effect of group were highly 
Table 2 HRV and spectral analysis of RR interval and SBP during controlled breathing ( 15 breaths per min) in healthy control participants and in patients with type 1 diabetes subdivided by diabetes duration and by autonomic score

\begin{tabular}{|c|c|c|c|c|c|c|c|}
\hline \multirow[t]{2}{*}{ Variable } & \multicolumn{4}{|c|}{$\begin{array}{l}\text { Patients with type } 1 \text { diabetes grouped by diabetes duration with } \\
\text { age-matched control groups }\end{array}$} & \multicolumn{3}{|c|}{$\begin{array}{l}\text { Patients with type } 1 \text { diabetes grouped by } \\
\text { autonomic score and all healthy controls pooled }\end{array}$} \\
\hline & $\begin{array}{l}\text { Long duration } \\
\text { of diabetes }\end{array}$ & $\begin{array}{l}\text { Healthy } \\
\text { controls }\end{array}$ & $\begin{array}{l}\text { Short duration } \\
\text { of diabetes }\end{array}$ & $\begin{array}{l}\text { Healthy } \\
\text { controls }\end{array}$ & $\mathrm{CAN}-0$ & CAN-1 & $\mathrm{CAN}-2$ \\
\hline$n$ & 37 & 37 & 117 & 36 & 126 & 23 & 5 \\
\hline \multicolumn{8}{|l|}{ Heart rate variability } \\
\hline SDNN & $31.4 \pm 2.9^{\mathrm{c}}$ & $30.9 \pm 2.2$ & $42.6 \pm 1.7$ & $49.7 \pm 4.5$ & $42.3 \pm 1.6^{\mathrm{e}}$ & $32.7 \pm 3.4$ & $11.8 \pm 1.6$ \\
\hline Ln RRI LF $\left(\mathrm{ms}^{2}\right)$ & $4.67 \pm 0.22^{\mathrm{d}}$ & $4.83 \pm 0.15$ & $5.55 \pm 0.09$ & $5.47 \pm 0.17$ & $5.55 \pm 0.08^{\mathrm{e}}$ & $4.74 \pm 0.25$ & $2.76 \pm 0.28$ \\
\hline Ln RRI HF $\left(\mathrm{ms}^{2}\right)$ & $4.71 \pm 0.24^{\mathrm{b}, \mathrm{d}}$ & $5.86 \pm 0.16$ & $6.12 \pm 0.10$ & $6.54 \pm 0.20$ & $5.99 \pm 0.10^{\mathrm{e}}$ & $5.15 \pm 0.33$ & $3.15 \pm 0.57$ \\
\hline RRI LF/HF & $1.63 \pm 0.35^{\mathrm{a}, \mathrm{c}}$ & $0.67 \pm 0.13$ & $0.93 \pm 0.12$ & $0.47 \pm 0.06$ & $1.06 \pm 0.12$ & $1.35 \pm 0.51$ & $0.93 \pm 0.36$ \\
\hline RRI nLF (\%) & $47.9 \pm 3.4^{\mathrm{b}}$ & $30.0 \pm 3.5$ & $37.2 \pm 1.8^{\mathrm{a}}$ & $28.0 \pm 2.6$ & $39.9 \pm 1.8$ & $39.8 \pm 4.4$ & $39.0 \pm 8.7$ \\
\hline RRI nHF (\%) & $50.2 \pm 3.5^{\mathrm{b}, \mathrm{c}}$ & $67.1 \pm 3.5$ & $61.0 \pm 1.8^{\mathrm{a}}$ & $70.7 \pm 2.6$ & $58.4 \pm 1.8$ & $58.5 \pm 4.4$ & $55.0 \pm 8.3$ \\
\hline \multicolumn{8}{|l|}{ SBP variability } \\
\hline $\log _{e}$ SBP LF $\left(\mathrm{mmHg}^{2}\right)$ & $0.74 \pm 0.14$ & $0.70 \pm 0.08$ & $0.97 \pm 0.10$ & $0.61 \pm 0.13$ & $1.04 \pm 0.08$ & $0.57 \pm 0.20$ & $-0.63 \pm 0.25$ \\
\hline
\end{tabular}

Data are mean \pm SEM

The differences between diabetic vs control groups, and between long vs short duration of diabetes were tested by two-level factorial ANOVA, whereas the differences between CAN groups were analysed by one-level factorial ANOVA and post hoc analysis with Tukey's test ${ }^{\mathrm{a}} p<0.05,{ }^{\mathrm{b}} p<0.01$ diabetic group vs age-matched healthy control group; ${ }^{\mathrm{c}} p<0.05,{ }^{\mathrm{d}} p<0.01$ long vs short duration of diabetes; ${ }^{\mathrm{e}} p<0.05 \mathrm{CAN}-0$ vs CAN-1

RRI, RR interval

significant $(p<0.001)$. There was also a significant interaction $(p<0.001)$ between intervention and group (controls vs short duration, $p<0.05$; controls vs long duration, $p<0.001$; short duration vs long duration, $p<0.001$ ).

After correction for age, the results of the groups with diabetes of long and short duration were superimposed (Fig. 1b). After age adjustment, the interactions between the healthy controls and the patients with a long $(p<0.001)$ and a short $(p<0.001)$ duration of diabetes remained significant, but the interaction between the groups with a different duration disappeared. Conversely, adjustment for age did not substantially modify the response to the change in breathing rate (Fig. 1b). The participants with definite denervation due to a heart transplant showed very low levels of resting BRS during controlled breathing, which remained unchanged with slow breathing.

Figure 2a demonstrates the effect of the intervention (deep breathing) in the diabetic patients grouped by autonomic score (CAN-0, CAN-1 and CAN-2). The main effects of the intervention and of the levels of autonomic involvement were highly significant $(p<0.001)$. The interaction between intervention and groups was also significant $(p<0.05)$. In all groups, except in CAN-2 and in hearttransplanted participants, deep breathing induced a significant increase in BRS $(p<0.001)$. After adjusting for age, the results remained unchanged, and the interactions between the controls and the CAN-0 and CAN-1-groups $(p<0.001)$ remained significant.

\section{Discussion}

In the present study, we demonstrated that patients with type 1 diabetes, irrespective of the disease duration, had a blunted BRS that in the majority of the patients could be restored by deep breathing. However, the response to deep breathing was lower in the patients with definite CAN, indicating that the discriminant for BRS responsiveness to deep breathing is the presence of autonomic neuropathy. Thus, the vast majority of our patients could still have a component of reversible autonomic involvement despite a long duration of diabetes. In addition, it seems that the effect of diabetes duration on BRS is mainly an effect of age, since the differences in the BRS between the duration groups vanished after adjusting for age.

These data extend our previous findings of the reversibility of a blunted BRS in patients with a short duration to patients with a long duration of type 1 diabetes [7]. Importantly, it has previously been demonstrated, both in healthy individuals and in individuals with hypertension, chronic heart failure or chronic obstructive pulmonary disease, that BRS can be enhanced by slow breathing. This occurs through a relative increase in vagal activity as marked by a reduction in heart rate and blood pressure, and a decline in sympathetic activity in small nerve fibres [2428]. The main role of BRS is to stabilise the blood pressure by modifying the heart rate. Thus, a measure that integrates information on both blood pressure and heart rate provides 

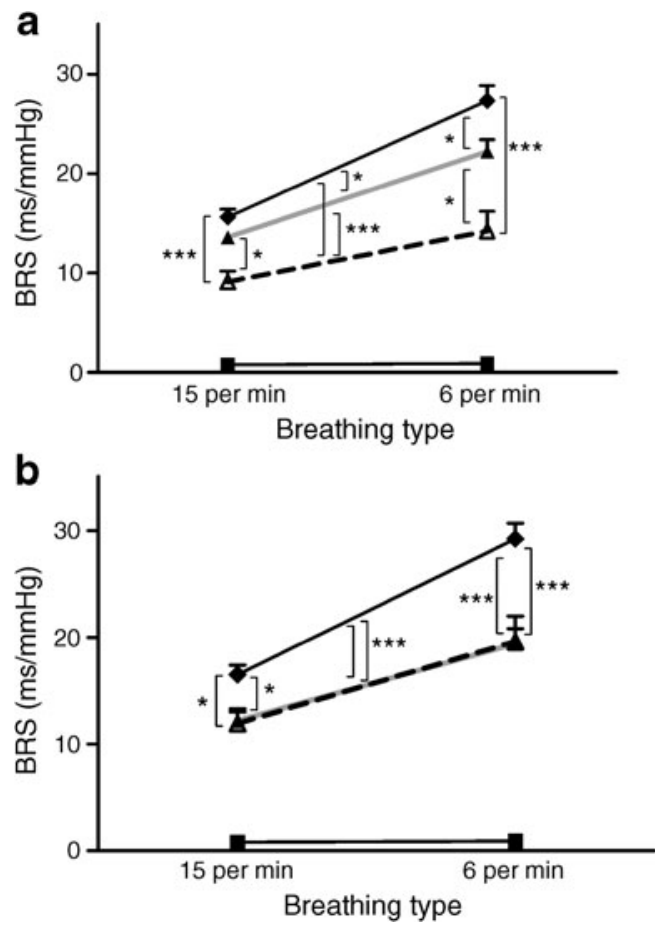

Fig. 1 Removal of the effect of diabetes duration on BRS by ageadjustment. The effect of breathing rate on the average BRS in healthy participants, in patients with type 1 diabetes grouped by diabetes duration, and in surgically denervated (heart-transplanted) patients is shown. Error bars represent SEM. The differences in response for deep breathing across the groups were tested with $3 \times 2$ mixed-design factorial ANOVA (one between-subjects factor with three groups [long duration of diabetes, short duration of diabetes, healthy controls] and one within-subjects factor with two conditions: average BRS when taking 15 vs six breaths per min). a No adjustments. b Adjustment for age. The intervention induced in all groups a significant increase in BRS $(p<0.001)$. Diamonds and solid line, healthy; black triangles and grey line, short duration; white triangles and dashed line, long duration; squares and solid line hearttransplanted. ${ }^{*} p<0.05, * * * p<0.001$

a better assessment than HRV alone of the main short-term cardiovascular regulatory system. Accordingly, slow breathing improves BRS by increasing HRV and blood pressure variability, but the induced fluctuations increase much more in the RR interval than in the blood pressure [23].

During sympathetic activation in healthy individuals, there is a predominance of LF oscillation in the SBP [29]. The LF power of SBP is also shown to increase with rising blood pressure levels in healthy individuals [30]. Interestingly, in the present study, the power in the LF band of the SBP was increased in the diabetic patients with a normal autonomic score, but was reduced in patients with a higher autonomic score (Table 2). Although not all comparisons between the groups reached statistical significance due to the small number of participants, this finding, along with an increased LF/HF ratio, is suggestive of a sympathetic predominance in patients with type 1 diabetes even in the absence of autonomic dysfunction (CAN-0), but a decline
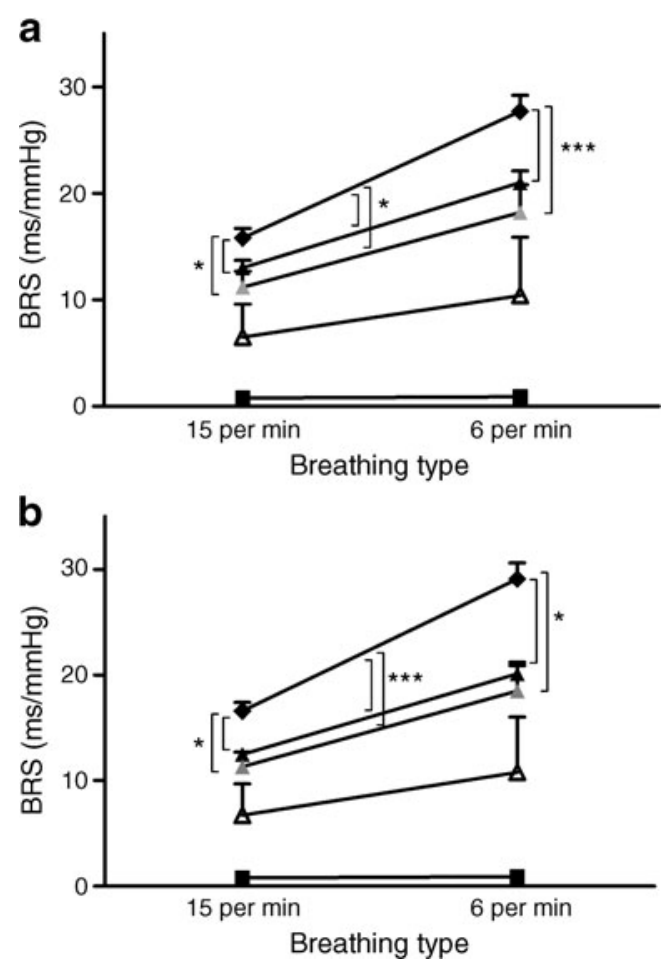

Fig. 2 Lack of influence of age on the effect of evident CAN on BRS. The effect of breathing rate on average BRS in healthy participants, in patients with diabetes grouped by the cardiovascular autonomic function tests (CAN-0: normal autonomic function; CAN-1: one abnormal autonomic function test; CAN-2: more than one abnormal autonomic function test), and in surgically denervated (heart-transplanted) patients. Error bars represent SEM. The differences in the response for deep breathing across the groups were tested with $3 \times 2$ mixed-design factorial ANOVA (one between-subjects factor with three groups [CAN-0, CAN-1 and healthy controls] and one withinsubjects factor with two conditions: average BRS when taking 15 vs six breaths per min). a No adjustments. b Adjustment for age. The intervention induced a significant increase in BRS $(p<0.001)$ in healthy controls and the CAN-0 and CAN-1 groups. Diamonds, healthy; black triangle, $\mathrm{CAN}-0$; grey triangle, $\mathrm{CAN}-1$; white triangle, CAN-2. ${ }^{*} p<0.05, * * * p<0.001$

in the sympathetic function with higher autonomic score and particularly in definite CAN.

It is of note that, until now, the low BRS and HRV have been ascribed to a loss of parasympathetic tone due to neuropathy. However, the increase in BRS by a breathing intervention would not have been achievable without a functioning parasympathetic system, as was seen in the heart-transplanted patients. In addition, similar findings could be obtained in heart failure or hypertension, when the cause of the low resting BRS was a higher sympathetic tone $[24,25,27]$, due to the reciprocal relationship of sympathetic and parasympathetic activity. Therefore our results point to elevated resting sympathetic tone rather than parasympathetic damage.

In type 1 diabetes, many factors other than parasympathetic neural damage could potentially influence BRS by 
increasing sympathetic activity. Oral glucose stimulates sympathetic activity and depresses parasympathetic activity, hence depressing the vagal arm of the BRS. The mechanism is not entirely established, although a role for insulin [31] or an increased osmolar load [32] has been suggested. Insulin therapy may also have an effect by stimulating the sympathetic nervous system and downregulating the vagal arm of the baroreflex [33-36]. This effect is well known in conditions of insulin resistance such as type 2 diabetes and obesity, and could also be present in type 1 diabetes, due to the insulin treatment. As such, it cannot be excluded as playing at least a part in our patients as well. Endothelial dysfunction and low-grade inflammation have also been related to autonomic imbalance [37-39] and could modify the resting level of autonomic function and BRS. Preliminary findings from our group suggest in addition a possible role of chronic tissue hypoxia. Taken together, the presence of most of these factors is well established in type 1 diabetes, and it would not be surprising if their influence on the sympatho-vagal balance would contribute to setting the resting BRS value.

Our main purpose was to elucidate the effect of duration of diabetes on the reversibility of the BRS by comparing two different groups of diabetic patients: one with a short and one with a long duration of disease. Obviously, it would have been rather difficult to obtain two such groups with equal ages. The BRS and essentially the vagal component of BRS is age dependent $[40,41]$. The differences between the two groups with a different duration disappeared after adjustment for age in terms of the resting level of the BRS and the response to deep breathing. The lack of association between long disease duration and the presence of autonomic dysfunction in our cohort is in line with the results of other recent studies [42-44]. However, the influence of the duration of diabetes on BRS has not to our knowledge been studied before. Importantly, the study by Larsen et al. demonstrated that, even after 30 years of diabetes, the mean $\mathrm{HbA}_{1 \mathrm{c}}<8.4 \%$ during a period of 18 years was associated with near-normal nerve conduction [42]. On the other hand, reduced cardiovascular autonomic reactivity has already been observed in newly diagnosed patients with type 1 diabetes [45, 46], supporting the role of factors other than long-standing hyperglycaemia in the pathogenesis of autonomic dysfunction. Long-term poor glycaemic control has been identified as a major contributor to the development and progression of diabetic CAN [2, 19, 42-44, 47, 48]. In the present study, $\mathrm{HbA}_{1 \mathrm{c}}$ showed a significant, although weak, inverse association with autonomic indices and BRS values (data not shown). However, despite only one single measurement of $\mathrm{HbA}_{1 \mathrm{c}}$, our findings support the central role of glycaemic control since patients with evident CAN had also higher $\mathrm{HbA}_{1 \mathrm{c}}$ values.
The only patients in whom we demonstrated a distinctively lower response to deep breathing were those with definite CAN. This could indicate a switch towards more prominent structural neural damage. However, even in these patients, there was still the capability to improve the BRS, and thus some functional reserve. The coexistence of nephropathy and CAN is well established, although it is presently not known what the causal relationship between nephropathy and neuropathy is $[3,4,49]$. In the present study, BRS did not correlate with urinary albumin excretion rate, although patients with evident CAN had a higher urinary albumin excretion rate.

In our patients, the prevalence of definite CAN was low, but this can be at least partly explained by the exclusion of patients on beta-blockers and of one patient who had received a kidney transplant. Thus, the low prevalence of CAN in the patients with long-term diabetes might be due to selection or survival bias. Accordingly, the proportion of more severe diabetic complications was clearly underestimated. On the other hand, the lower prevalence of complications allows us to better clarify the role of duration per se. In this study, respiration could not be measured directly; however, it was actively and visually controlled.

The practical implications of this new approach are evident as the functional nature of early alterations might enable interventions capable of retarding the onset and progression of autonomic derangement. It is important to detect the time point in the natural history of the disease at which the organic dysfunction predominates in order to be able to initiate effective preventive measures while the abnormalities are still reversible. Previous studies have established a positive role for physical training to correct the functional autonomic abnormality in heart failure [14, 15] and hypertension [16]. Both conditions are characterised by a sympathetic predominance and a reduced BRS of functional origin. Early autonomic abnormalities also seem to be favourably influenced by physical exercise in type 2 diabetes [17, 18], again suggesting that these abnormalities can be partly corrected in diabetes.

In conclusion, patients with type 1 diabetes, irrespective of disease duration, have a blunted BRS that in the majority of the patients can be restored by slow breathing. Moreover, even after a long duration of diabetes, the abnormal BRS is at least in part of functional origin in most of the patients, and the decline in the BRS is mainly due to age.

Acknowledgements The study was funded by the Folkhälsan Research Foundation, Wilhelm and Else Stockmann Foundation, Signe and Ane Gyllenberg Foundation, Sigrid Juselius Foundation, Medicinska understödsföreningen Liv och Hälsa, Waldemar von Frenckell Foundation, and a special governmental grant for health sciences research (no. 7301).

Duality of interest statement The authors declare that there is no duality of interest associated with this manuscript. 


\section{References}

1. Kempler P, Tesfaye S, Chaturvedi N et al (2002) Autonomic neuropathy is associated with increased cardiovascular risk factors: the EURODIAB IDDM Complications Study. Diabet Med 19:900-909

2. Forsen A, Kangro M, Sterner G et al (2004) A 14-year prospective study of autonomic nerve function in type 1 diabetic patients: association with nephropathy. Diabet Med 21:852-858

3. Lefrandt JD, Hoogenberg K, van Roon AM, Dullaart RP, Gans RO, Smit AJ (1999) Baroreflex sensitivity is depressed in microalbuminuric type I diabetic patients at rest and during sympathetic manoeuvres. Diabetologia 42:1345-1349

4. Astrup AS, Tarnow L, Rossing P, Hansen BV, Hilsted J, Parving HH (2006) Cardiac autonomic neuropathy predicts cardiovascular morbidity and mortality in type 1 diabetic patients with diabetic nephropathy. Diabetes Care 29:334-339

5. Maser RE, Mitchell BD, Vinik AI, Freeman R (2003) The association between cardiovascular autonomic neuropathy and mortality in individuals with diabetes: a meta-analysis. Diabetes Care 26:1895-1901

6. Cameron NE, Eaton SE, Cotter MA, Tesfaye S (2001) Vascular factors and metabolic interactions in the pathogenesis of diabetic neuropathy. Diabetologia 44:1973-1988

7. Rosengard-Barlund M, Bernardi L, Fagerudd J et al (2009) Early autonomic dysfunction in type 1 diabetes: a reversible disorder? Diabetologia 52:1164-1172

8. La Rovere MT, Bigger JT Jr, Marcus FI, Mortara A, Schwartz PJ (1998) Baroreflex sensitivity and heart-rate variability in prediction of total cardiac mortality after myocardial infarction. ATRAMI (Autonomic Tone and Reflexes After Myocardial Infarction) Investigators. Lancet 351:478-484

9. De Ferrari GM, Sanzo A, Bertoletti A, Specchia G, Vanoli E, Schwartz PJ (2007) Baroreflex sensitivity predicts long-term cardiovascular mortality after myocardial infarction even in patients with preserved left ventricular function. J Am Coll Cardiol 50:2285-2290

10. La Rovere MT, Pinna GD, Maestri R et al (2003) Short-term heart rate variability strongly predicts sudden cardiac death in chronic heart failure patients. Circulation 107:565-570

11. Weston PJ, James MA, Panerai R et al (1996) Abnormal baroreceptor-cardiac reflex sensitivity is not detected by conventional tests of autonomic function in patients with insulindependent diabetes mellitus. Clin Sci Lond 91:59-64

12. Frattola A, Parati G, Gamba P et al (1997) Time and frequency domain estimates of spontaneous baroreflex sensitivity provide early detection of autonomic dysfunction in diabetes mellitus. Diabetologia 40:1470-1475

13. Ziegler D, Laude D, Akila F, Elghozi JL (2001) Time- and frequency-domain estimation of early diabetic cardiovascular autonomic neuropathy. Clin Auton Res 11:369-376

14. Coats AJ, Adamopoulos S, Radaelli A et al (1992) Controlled trial of physical training in chronic heart failure. Exercise performance, hemodynamics, ventilation, and autonomic function. Circulation 85:2119-2131

15. Piepoli MF, Davos C, Francis DP, Coats AJ, Collaborative ExTraMATCH (2004) Exercise training meta-analysis of trials in patients with chronic heart failure (ExTraMATCH). BMJ 328:189

16. Laterza MC, de Matos LDNJ, Trombetta IC et al (2007) Exercise training restores baroreflex sensitivity in never-treated hypertensive patients. Hypertension 49:1298-1306

17. Loimaala A, Huikuri HV, Koobi T, Rinne M, Nenonen A, Vuori I (2003) Exercise training improves baroreflex sensitivity in type 2 diabetes. Diabetes 52:1837-1842
18. Figueroa A, Baynard T, Fernhall B, Carhart R, Kanaley JA (2007) Endurance training improves post-exercise cardiac autonomic modulation in obese women with and without type 2 diabetes. Eur J Appl Physiol 100:437-444

19. DCCT Research Group (1998) The effect of intensive diabetes therapy on measures of autonomic nervous system function in the Diabetes Control and Complications Trial (DCCT). Diabetologia 41:416-423

20. Makimattila S, Schlenzka A, Mantysaari M et al (2000) Predictors of abnormal cardiovascular autonomic function measured by frequency domain analysis of heart rate variability and conventional tests in patients with type 1 diabetes. Diabetes Care 23:1686-1693

21. Piha SJ (1991) Cardiovascular autonomic reflex tests: normal responses and age-related reference values. Clin Physiol 11:277290

22. Tesfaye SFRCP, Boulton AJM, Dyck PJ et al (2010) Diabetic neuropathies: update on definitions, diagnostic criteria, estimation of severity, and treatments. Diabetes Care 33:2285-2293

23. Bernardi L, de Barbieri G, Rosengard-Barlund M, Makinen VP, Porta C, Groop PH (2010) New method to measure and improve consistency of baroreflex sensitivity values. Clin Auton Res 20:353-361

24. Naughton MT, Floras JS, Rahman MA, Jamal M, Bradley TD (1998) Respiratory correlates of muscle sympathetic nerve activity in heart failure. Clin Sci Lond 95:277-285

25. Goso Y, Asanoi H, Ishise H et al (2001) Respiratory modulation of muscle sympathetic nerve activity in patients with chronic heart failure. Circulation 104:418-423

26. Bernardi L, Porta C, Spicuzza L et al (2002) Slow breathing increases arterial baroreflex sensitivity in patients with chronic heart failure. Circulation 105:143-145

27. Joseph CN, Porta C, Casucci G et al (2005) Slow breathing improves arterial baroreflex sensitivity and decreases blood pressure in essential hypertension. Hypertension 46:714-718

28. Raupach T, Bahr F, Herrmann P et al (2008) Slow breathing reduces sympatho-excitation in chronic obstructive pulmonary disease. Eur Respir J 32:387-392

29. Pagani M, Montano N, Porta A et al (1997) Relationship between spectral components of cardiovascular variabilities and direct measures of muscle sympathetic nerve activity in humans. Circulation 95:1441-1448

30. Lucini D, Mela GS, Malliani A, Pagani M (2002) Impairment in cardiac autonomic regulation preceding arterial hypertension in humans: insights from spectral analysis of beat-by-beat cardiovascular variability. Circulation 106:2673-2679

31. Berne C, Fagius J (1993) Metabolic regulation of sympathetic nervous system activity: lessons from intraneural nerve recordings. Int J Obes Relat Metab Disord 17(Suppl 3):S2-S6, discussion S22

32. Hoffman RP, Hausberg M, Sinkey CA, Anderson EA (1999) Hyperglycemia without hyperinsulinemia produces both sympathetic neural activation and vasodilation in normal humans. J Diab Complications 13:17-22

33. Scherrer U, Sartori C (1997) Insulin as a vascular and sympathoexcitatory hormone: implications for blood pressure regulation, insulin sensitivity, and cardiovascular morbidity. Circulation 96:4104-4113

34. Anderson EA, Hoffman RP, Balon TW, Sinkey CA, Mark AL (1991) Hyperinsulinemia produces both sympathetic neural activation and vasodilation in normal humans. J Clin Invest $87: 2246-2252$

35. Emdin M, Gastaldelli A, Muscelli E et al (2001) Hyperinsulinemia and autonomic nervous system dysfunction in obesity: effects of weight loss. Circulation 103:513-519 
36. Takagi M, Tanaka Y, Yamasaki Y et al (2003) Responsiveness of insulin-induced cardiac sympathetic nerve activation associates with blood pressure regulation in diabetics. Am J Physiol Endocrinol Metab 284:E1022-E1026

37. Lambert E, Sari CI, Dawood T et al (2010) Sympathetic nervous system activity is associated with obesity-induced subclinical organ damage in young adults. Hypertension 56:351-358

38. Lanza GA, Pitocco D, Navarese EP et al (2007) Association between cardiac autonomic dysfunction and inflammation in type 1 diabetic patients: effect of beta-blockade. Eur Heart J 28:814820

39. Gonzalez-Clemente J, Vilardell C, Broch M et al (2007) Lower heart rate variability is associated with higher plasma concentrations of IL-6 in type 1 diabetes. Eur J Endocrinol 157:31-38

40. Laitinen T, Hartikainen J, Vanninen E, Niskanen L, Geelen G, Lansimies E (1998) Age and gender dependency of baroreflex sensitivity in healthy subjects. J Appl Physiol 84:576-583

41. Fauvel J, Cerutti C, Mpio I, Ducher M (2007) Aging process on spectrally determined spontaneous baroreflex sensitivity: a 5-year prospective study. Hypertension 50:543-546

42. Larsen JR, Sjoholm H, Hanssen KF, Sandvik L, Berg TJ, DahlJorgensen K (2003) Optimal blood glucose control during 18 years preserves peripheral nerve function in patients with 30 years' duration of type 1 diabetes. Diabetes Care 26:2400-2404

43. Reichard P, Jensen-Urstad K, Ericsson M, Jensen-Urstad M, Lindblad LE (2000) Autonomic neuropathy—a complication less pronounced in patients with type 1 diabetes mellitus who have lower blood glucose levels. Diabet Med 17:860-866

44. Witte DR, Tesfaye S, Chaturvedi N et al (2005) Risk factors for cardiac autonomic neuropathy in type 1 diabetes mellitus. Diabetologia 48:164-171

45. Keresztes K, Istenes I, Hermanyi Z, Vargha P, Barna I, Kempler P (2003) Risk factors of autonomic and sensory nerve dysfunction in patients with newly diagnosed type 1 diabetes. Diabetes Care 26:2213-2214

46. Ziegler D, Dannehl K, Volksw D, Muhlen H, Spuler M, Gries FA (1992) Prevalence of cardiovascular autonomic dysfunction assessed by spectral analysis and standard tests of heart-rate variation in newly diagnosed IDDM patients. Diabetes Care 15:908-911

47. Larsen JR, Sjoholm H, Berg TJ et al (2004) Eighteen years of fair glycemic control preserves cardiac autonomic function in type 1 diabetes. Diabetes Care 27:963-966

48. Pop-Busui R, Low PA, Waberski BH et al (2009) Effects of prior intensive insulin therapy on cardiac autonomic nervous system function in type 1 diabetes mellitus: the Diabetes Control and Complications Trial/Epidemiology of Diabetes Interventions and Complications study (DCCT/EDIC). Circulation 119:2886-2893

49. Torffvit O, Lindqvist A, Agardh CD, Pahlm O (1997) The association between diabetic nephropathy and autonomic nerve function in type 1 diabetic patients. Scand J Clin Lab Invest 57:183-191 